\title{
Mixed exposure to bacterial lipopolysaccharide (LPS) and seafood proteases augment inflammatory signalling in an airway epithelial cell model (A549).
}

Submitted to Toxicology and Industrial Health in December, 2014.

Sampada S.Bhagwat ${ }^{\text {a, b }}$, Anett K. Larsen ${ }^{\text {c }}$, Ole-Morten Seternes ${ }^{\text {d }}$, Berit E. Bang a, b,*

a) Department of Occupational and Environmental Medicine, University Hospital North Norway, NO-9038 Tromsø, Norway.

b) Department of Medical Biology, Faculty of Health Sciences, UiT The Arctic University of Norway, NO-9037 Troms $\varnothing$, Norway.

c) Department of Arctic and Marine Biology, Faculty of Fisheries and Economics, UiT The Arctic University of Norway, NO-9037 Troms $\varnothing$, Norway.

d) Department of Pharmacy, Faculty of Health Sciences, UiT The Arctic University of Norway, NO-9037 Troms $\varnothing$, Norway.

\section{*Corresponding author}

Berit E. Bang, Department of Occupational and Environmental Medicine, University Hospital North Norway.

P.O.Box 16, N-9038 Troms $\emptyset$, Norway.

Tel. +4777627463

Mobile: +4797133223

E-mail address: berit.bang@unn.no 


\begin{abstract}
Seafood industry workers exhibit an increased prevalence of respiratory symptoms due to exposure to bioaerosols containing a mixture of bioactive agents. In this study a human pulmonary epithelial cell model (A549) was exposed to mixtures of bacterial lipopolysaccharide (LPS) and either protease-activated receptor-2 (PAR-2) agonists SLIGKV-NH2, purified salmon (Salmo salar) trypsin or purified king crab (Paralithodes camtschaticus) trypsin. The inflammatory response was measured based on nuclear factor kappa B (NF- $\mathrm{B}$ ) activation of transcription in a luciferase reporter gene assay and interleukin-8 (IL-8) secretion in an enzymelinked immunosorbent assay (ELISA). We observed that mixtures of SLIGKV-NH $\mathrm{N}_{2}$ or trypsins with LPS augmented the activation of NF- $\kappa \mathrm{B}$ and secretion of IL-8. The effect on IL- 8 secretion was synergistic when both trypsins and LPS were used in the lower concentration range. The results demonstrate that exposure to mixtures of agents that are relevant to seafood industry workplaces may lead to increased inflammatory signalling compared to exposure to the individual agents alone. Furthermore, the results indicate that synergism may occur with the combined exposure to seafood trypsins with and LPS, and is most likely to occur when exposure to either agent is low.
\end{abstract}




\section{Introduction}

Respiratory symptoms associated with occupational seafood exposure are common, and several studies have reported that workers in the seafood industry are at risk of developing respiratory disorders (Jeebhay and Cartier, 2010; Jeebhay et al., 2001). Workers in this industry are exposed to bioaerosols generated during seafood handling and processing (Jeebhay and Cartier, 2010). The inhalation of bioaerosols containing allergens, enzymes, microorganisms, endotoxins and other bioactive agents is the main cause of the observed respiratory problems (Bang et al., 2005; Shiryaeva et al., 2014).

In occupational settings, workers are exposed to several bioactive substances that co- exist in the bioaerosol mixtures. It is well known that exposure to mixtures may result in combined effects due to interactions between the different substances (Kartono and Maibach, 2006; Wade et al., 2002; Boyd et al., 1990).

Endotoxin is the major constituent of the outer membrane of gram-negative bacteria. The terms endotoxin and lipopolysaccharide (LPS) are sometimes used interchangeably in the literature. However, the term LPS denotes the chemically pure substance that is free from other chemical compounds, whereas, the term endotoxin refers to the toxin as the compound is present the bacterial cell wall. LPS is soluble in water and consists of a lipid A (phosphoglycolipid) component and a polysaccharide component, which are responsible for the toxicity and immunogenicity, respectively (Liebers et al., 2006). Gram-negative bacteria are ubiquitous in nature, and endotoxins are thus abundantly present in the environment. Human environmental exposure to endotoxin is mainly via inhalation. Studies have reported the presence of airborne endotoxin in various occupational environments, such as agricultural work, food industries, the textile industry, saw mills, waste handling and processing, breweries and paper mills (Rylander, 2002; Michel, 2003; al-Dagal and Fung, 1990). In the seafood industry, Gram-negative bacteria are likely to be present in several processes, and endotoxins have been measured in these work environments (Bang et al., 2005; Shiryaeva et al., 2014). Accumulating evidence suggests that exposure to environmental endotoxins is linked to airway inflammation, bronco constriction, decreased lung function, hypersensitive pneumonitis, chronic bronchitis and asthma (Michel, 2003; Michel, 2001; Schwartz et al., 1995; Thorn, 2001; Hernandez et al., 2011). It has been documented that endotoxin induces 
the activation, translocation and DNA binding of nuclear factor-kappa B (NF- $\kappa \mathrm{B})$ (Zhang and Ghosh, 2000; Hernandez et al., 2011; Aul et al., 2012; Guha and Mackman, 2001), a key regulator of immune and inflammatory responses via toll like receptors, and trigger the generation of a variety of inflammatory cytokines, TNF- $\alpha$, growth factors, and matrix metalloproteinases (MMPs) (O'Grady et al., 2001; Michel et al., 2007).

The role of proteases in promoting the synthesis and release of inflammatory mediators such as cytokines, prostanoids, growth factors and MMP has been previously demonstrated (Bang et al., 2009; Larsen et al., 2008; Bhagwat et al., 2014; Lee et al., 2010; Page et al., 2006; Asokananthan et al., 2002; Vliagoftis et al., 2001). Our previous studies have shown that the trypsin present in seafood is capable of eliciting an inflammatory response via the activation of NF- $\kappa \mathrm{B}$ and the secretion of interleukin-8 (IL-8) in a human alveolar cell line and of IL-8 and MMP in a skin keratinocytic cell line via a mechanism that involves protease-activated receptor-2 (PAR-2) (Bhagwat et al., 2014; Larsen et al., 2008; Larsen et al., 2011). Studies performed by Rallabhandi et al. (2008) demonstrated that PAR-2 and toll-like receptor-4 (TLR-4) or cooperatively resulted in an enhanced NF- $\kappa B$ response, which suggests an important role for cooperativity in the inflammatory response to mixtures that contain LPS and PAR-2 agonists (Rallabhandi et al., 2008). Other studies have also demonstrated that concurrent exposure to LPS and PAR-2 agonists synergistically augments the inflammatory signals (Ostrowska et al., 2007).

Therefore, in this study, we chose to investigate whether mixtures of LPS with either salmon (Salmo salar) trypsin or king crab (Paralithodes camtschaticus) trypsin were able to stimulate a cellular response related to inflammation in the human airway epithelial cell line A549 and to determine whether such mixtures had combined effects on the generation of NF$\kappa \mathrm{B}$ and the release of IL-8. 


\section{Materials and methods}

\subsection{Materials}

A549 cells (ATCC; no CCL-185) were obtained from American Type Culture Collection and the A549-NF-кB-luc cells (RC0002) were obtained from Panomics, CA, USA. Dulbecco's minimum essential medium/Ham's F12 medium (1:1), foetal calf serum, L-glutamine and penicillin-streptomycin were purchased from Gibco, NY, USA. The 12 well plates $\left(4 \mathrm{~cm}^{2}\right)$ were obtained from Nunc, Thermo Scientific, MA, USA. The PAR-2 agonist peptide SLIGKV-NH 2 (H-Ser-Leu-Ile-Gly-Lys-Val-NH $\left.{ }_{2}\right)$ was purchased from Bachem, Bubendorf, Switzerland. The enzyme-linked immunosorbent assay (ELISA) kit was obtained from BD Biosciences, NJ, USA. The purified salmon trypsin was kindly provided by Dr. Nils Peder Willassen (University of Troms $\varnothing$, Norway) (Outzen et al., 1996), and the king crab trypsin was provided by Dr. Galina N. Rudenskaia (Moscow State University, Russia) (Rudenskaia et al., 1998). LPS from Escherichia coli O111:B4, hygromycin B and the non-enzymatic cell dissociation solution were purchased from Sigma-Aldrich, MO, USA. The Dual-light Luciferase Reporter Gene Assay System was obtained from Applied Biosystems, CA, USA, and the Dc Protein Assay kit was purchased from Bio-Rad, CA, USA.

\subsection{Cell Culture}

The A549 cells, a human pulmonary epithelial cell line, and A549/NF- $\kappa B-l u c$ cells, a human

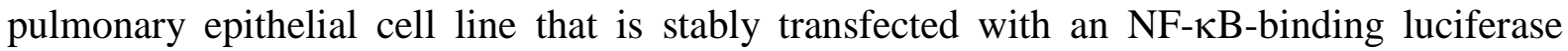
reporter construct, were cultured in Dulbecco's minimum essential medium/Ham's F12 medium (1:1) supplemented with $10 \%$ foetal calf serum, $2 \mathrm{mM}$ L-glutamine, $50 \mathrm{IU} / \mathrm{ml}$ penicillin and $50 \mu \mathrm{g} / \mathrm{ml}$ streptomycin. In addition, the culture medium for the A549/NF- $\mathrm{BB}$ luc cells was supplemented with $100 \mu \mathrm{g} / \mathrm{ml}$ hygromycin $\mathrm{B}$. The cells were passaged using a non-enzymatic cell dissociation solution.

\subsection{Cell Stimulation experiment}

A549 cells were seeded into 12 -well plates at a density of $1 \times 10^{5}$ cells/well. After reaching $80 \%$ confluence, the cells were starved of serum overnight. The cells were then subjected to stimulation with purified salmon trypsin, purified king crab trypsin, or the PAR-2 agonist 
peptide SLIGKV-NH 2 and LPS from E.coli O111:B4 for 6 hours. The culture supernatant was collected and stored at $-20^{\circ} \mathrm{C}$.

\subsection{Protease activity}

The enzymatic activity of the purified salmon and king crab trypsins was analysed with a serine protease assay as previously described (Outzen et al., 1996; Erlanger et al., 1961). Briefly, the kinetic measurement was determined by the hydrolysis of a chromogenic substrate, Na-benzoyl-D-L-arginine 4-nitroanilide hydrochloride (DL-BAPNA). The absorbance was measured spectrophotometrically at $405 \mathrm{~nm}$ for 10 minutes at room temperature and expressed as Units/ml (U/ml). One activity unit was defined as $1 \mu \mathrm{mol}$ of substrate hydrolysed per minute using an extinction coefficient of $8800 \mathrm{M}^{-1} \mathrm{~cm}^{-1}$.

\subsection{Quantitative analysis of IL-8 secretion}

The amount of IL-8 in the cell culture supernatant was measured with an ELISA kit according to the protocol described in the manufacturer's instructions. The absorbance was measured with an iEMS Multiscan EX (Thermo Labsystems). The amount of IL-8 produced was calculated and expressed as $\mathrm{pg} / \mathrm{ml}$.

\subsection{Reporter gene assay}

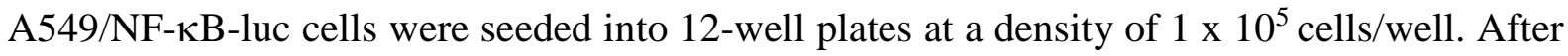
reaching $80 \%$ confluence, the cells were starved of serum overnight. The cells were then subjected to stimulation with purified salmon trypsin, purified king crab trypsin, or the PAR-2 peptide agonist SLIGKV-NH 2 and LPS from E.coli O111: B4 for 6 hours. The cells were then lysed, and the luciferase activity in the cell culture lysates was measured with a Dual-Light Luciferase Reporter Gene Assay System according to the manufacturer's instructions. The luciferase activity was measured with a Luminoskan RT dual injection luminometer (Labsystems). The total protein concentration in each cell lysate was measured with a DC Protein Assay and used to normalise the luciferase values. 


\subsection{Statistical Analysis}

The response data were regarded as synergistic when exposure to two combined stimulating agents resulted in response levels that exceeded the sum of the response to the respective agents alone at the same concentrations. Student's $\boldsymbol{t}$ tests for independent samples (SPSS) were performed to compare the group data. Differences were regarded as significant for $p$ values $<0.05$. 


\section{Results}

\subsection{LPS enhances the secretion of IL-8 in human pulmonary epithelial cells.}

To verify whether LPS (endotoxin) induces the secretion of IL-8 in a human pulmonary epithelial cell model, A549 cells were stimulated with different concentrations of bacterial endotoxin (LPS) for 6 hours. LPS induced the secretion of IL-8 in A549 cells in a dose dependent manner (Figure 1). The maximum stimulation was observed when the A549 cells were stimulated with $100 \mu \mathrm{g} / \mathrm{ml}$ LPS, and the lowest stimulation was observed when the A549 cells were stimulated with $10 \mu \mathrm{g} / \mathrm{ml}$ LPS. Concentrations that were lower than $10 \mu \mathrm{g} / \mathrm{ml}$ LPS did not induce an increase in the levels of IL-8 compared to the basal levels.

\subsection{Effect of LPS (endotoxin) and SLIGKV-NH2 on the secretion of IL-8 in human pulmonary epithelial cells.}

To determine whether a combination of LPS (endotoxin) and SLIGKV-NH 2 (a synthetic PAR-2 agonist peptide) had an effect on the level of IL-8 in a human pulmonary epithelial cell line, A549 cells were stimulated with different concentrations of SLIGKV-NH 2 alone or in combination with $10 \mu \mathrm{g} / \mathrm{ml}$ LPS. Figure 2 shows that both SLIGKV-NH 2 and LPS individually lead to an increase in the secretion of IL-8, whereas a mixture of SLIGKV$\mathrm{NH}_{2}$ and LPS resulted in a further increase in the levels of IL-8 compared to either of the agents alone.

\subsection{Seafood trypsin and LPS synergistically induce the secretion of IL-8 in human pulmonary epithelial cells.}

To determine whether LPS (endotoxin) along with purified salmon trypsin or king crab trypsin had a synergistic effect on the induction of IL-8 secretion in a human pulmonary epithelial cell line, A549 cells were stimulated with different concentrations of purified salmon trypsin $(0.2,0.6 \mathrm{mU} / \mathrm{ml})$ or king crab trypsin $(0.01,0.015,0.02 \mathrm{mU} / \mathrm{ml})$ alone and with mixtures of the same concentrations of salmon or king crab trypsin and LPS (10 
$\mu \mathrm{g} / \mathrm{ml})$. The results displayed in Figure $3 \mathrm{~A}$ and $3 \mathrm{~B}$ demonstrate that the mixtures of LPS and salmon/king crab trypsin induced an increase in the levels of IL-8. A synergistic effect was observed when the A549 cells were stimulated with a mixture of $10 \mu \mathrm{g} / \mathrm{ml}$ LPS with $0.2 \mathrm{mU} / \mathrm{ml}$ salmon trypsin or with $0.01 \mathrm{mU} / \mathrm{ml}$ or $0.015 \mathrm{mU} / \mathrm{ml}$ king crab trypsin. The maximum synergistic response was observed with the mixtures of $0.2 \mathrm{mU} / \mathrm{ml} \mathrm{salmon}$ trypsin + LPS and $0.015 \mathrm{mU} / \mathrm{ml}$ king crab trypsin + LPS with a 4-fold increase in the IL8 levels compared to the cells treated with either type of trypsin or LPS alone. Higher concentrations of salmon trypsin in the mixture, $0.6 \mathrm{mU} / \mathrm{ml}+$ LPS resulted in a 1.4-fold increase in the IL-8 levels compared to the cells treated with $0.6 \mathrm{mU} / \mathrm{ml}$ salmon trypsin alone.

\subsection{Effect of variable LPS (endotoxin) concentrations}

To determine the role of variable LPS (endotoxin) concentrations in combination with the seafood trypsins, A549 cells were exposed to a mixture of purified salmon trypsin $(0.2$ $\mathrm{mU} / \mathrm{ml})$ or king crab trypsin $(0.015 \mathrm{mU} / \mathrm{ml})$ and/or higher concentrations of LPS (25 $\mu \mathrm{g} / \mathrm{ml}$ and $50 \mu \mathrm{g} / \mathrm{ml})$. Figure 4 illustrates that a mixture of different concentrations of LPS and the salmon or king crab trypsins enhanced the levels of IL-8. A synergistic effect was observed when the A549 cells were stimulated with a mixture of $0.015 \mathrm{mU} / \mathrm{ml} \mathrm{king} \mathrm{crab}$ trypsin $+25 \mu \mathrm{g} / \mathrm{ml}$ LPS. When the A549 cells were stimulated with a mixture of 0.2 $\mathrm{mU} / \mathrm{ml}$ salmon trypsin $+50 \mu \mathrm{g} / \mathrm{ml}$ LPS, we observed an increase in the level of IL-8 compared to the cells treated with LPS and salmon trypsin alone, but this increase was less than the sum of the effects of both agents.

\subsection{Mixtures of LPS (endotoxin) with SLIGKV-NH2, salmon or king crab trypsin stimulate the generation of NF- $\mathrm{KB}$ in human pulmonary epithelial cells}

To investigate whether the activation of $N F-\kappa B$ is stimulated by the exposure of human pulmonary epithelial cells to a mixture of LPS (endotoxin) together with salmon trypsin 
or king crab trypsin, A549/NF-kB-luc cells were exposed to different concentrations of SLIGKV-NH $\mathrm{N}_{2}(10 \mu \mathrm{M})$, purified salmon trypsin $(0.2,0.6 \mathrm{mU} / \mathrm{ml})$ and king crab trypsin $(0.01,0.015,0.02 \mathrm{mU} / \mathrm{ml})$ alone and mixtures of the same concentrations of SLIGKV$\mathrm{NH}_{2}$ and the purified salmon or king crab trypsins with LPS $(10 \mu \mathrm{g} / \mathrm{ml})$. The results in Figure 5 indicate that the mixture of endotoxin (LPS) with SLIGKV-NH trypsin or king crab trypsin stimulate the generation of NF- $\kappa \mathrm{B}$, as did each of the agents alone. The maximum response was generated with a mixture $0.015 \mathrm{mU} / \mathrm{ml}$ king crab

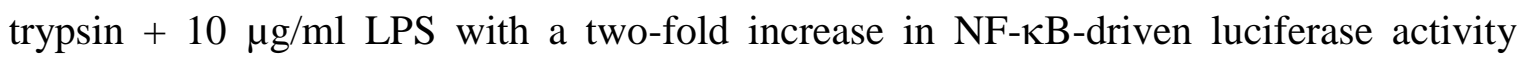
compared to the effect of purified king crab trypsin alone. Higher concentrations of purified king crab trypsin resulted in an increase in the NF- $\kappa \mathrm{B}-$ driven luciferase activity compared to the untreated cells but did not exhibit a significant increase in the generation of NF- $\mathrm{KB}$ when used in a mixture of trypsin and LPS. A mixture of purified salmon trypsin $(0.6 \mathrm{mU} / \mathrm{ml})+10 \mu \mathrm{g} / \mathrm{ml}$ LPS stimulated the generation of NF- $\mathrm{KB}$ with a 1.5 -fold increase compared to the cells treated with salmon trypsin alone. 


\section{Discussion}

In this study, we focused on the inflammatory responses of airway epithelial cells elicited by exposure to relevant agents in bioaerosols present in seafood industry work environments. The effects of the agents alone and in combination are highlighted. Seafood proteases and endotoxin (LPS) are anticipated to be relevant exposure mixtures in occupational environments in the seafood industry.

In our previous studies, we demonstrated that seafood proteases are capable of stimulating inflammatory responses in airway epithelial cells via PAR-2. PAR-2 agonists together with LPS have previously been shown to potentiate the stimulation of the inflammatory mediator IL-8 in cell models (Ostrowska et al., 2007).

It has been previously documented that endotoxin (LPS) induces the up-regulation of the secretion of pro-inflammatory mediators such as IL-6, IL-8, TNF- $\alpha$, and IL-1 $\beta$ (Reddi et al., 2003; Guha and Mackman, 2001; Rylander, 2002; Thorn, 2001). Figure one shows that bacterial LPS also elicits a dose-dependent increase in IL-8 secretion in these A549 cells. Similarly, the ability of proteases to stimulate the secretion of innate inflammatory mediators is well known (Bang et al., 2009; Bhagwat et al., 2014; Larsen et al., 2008; Larsen et al., 2011; Lee et al., 2010; Bhat et al., 2003; Kato et al., 2009; Kauffman et al., 2000). The involvement of PAR-2 in serine protease-mediated up-regulation of inflammatory mediators has been previously documented (Sun et al., 2001; Hong et al., 2004; Page et al., 2006; Bhagwat et al., 2014; Larsen et al., 2008; Larsen et al., 2011). Based on our own previous studies, salmon trypsin as well as king crab trypsin are capable of eliciting a dose-dependent increase in NF- $\kappa \mathrm{B}$ activation and IL-8 secretion via PAR-2 in A549 cells (Larsen et al., 2008).

In addition, the augmented activation of inflammatory signals with concurrent PAR-2 activation and LPS exposure has been described (Ostrowska et al., 2007; Chi et al., 2001). In this study, we were interested in investigating whether combinations of the PAR-2 agonist SLIGKV-NH 2 or PAR-2 activating seafood trypsins with LPS could produce enhanced inflammatory signals in the form of $\mathrm{NF}-\kappa \mathrm{B}$-activation as well as IL-8 
stimulation in our cell model. The combined effects with concomitant exposure to these agents have not been previously described.

The results in Figure 5, reveal an augmented activity of NF- $\kappa \mathrm{B}$ in the samples treated with a mixture of LPS and SLIGKV-NH 2 or seafood trypsins compared to those treated with either of the agents alone (Figure 5). A significant 2-fold increase in NF- $\kappa \mathrm{B}$ was observed in the cells treated with a mixture of $0.015 \mathrm{mU} / \mathrm{ml}$ king crab trypsin $+10 \mu \mathrm{g} / \mathrm{ml}$ LPS, and a 1.5-fold increase was observed in the cells treated with $0.6 \mathrm{mU} / \mathrm{ml}$ salmon trypsin $+10 \mu \mathrm{g} / \mathrm{ml}$ LPS. These results confirm the previous finding that there are differences in the salmon and king crab trypsins regarding the ability of these proteases to generate inflammatory signals (Larsen et al., 2011). The results further indicate that concurrent exposure to LPS and seafood trypsin increases the generation of transcription factor $\mathrm{NF}-\kappa \mathrm{B}$ compared to exposure to the individual agents, and thus augments the inflammatory signals in the A549 cell line.

Further, to investigate whether the increase in $\mathrm{NF}-\kappa \mathrm{B}$ signals extents to inflammatory cytokines, we examined the effect on IL- 8 of the PAR-2 agonist peptide SLIGKV- $\mathrm{NH}_{2}$ and seafood trypsins in combination with LPS. We found a significant increase in the IL-8 levels when the A549 cells were treated with mixtures consisting of variable concentrations of the PAR-2 agonist or seafood trypsins with $10 \mu \mathrm{g} / \mathrm{ml}$ LPS (Figures 2, $3 \mathrm{~A}$ and $3 \mathrm{~B})$. With lower concentrations of the seafood trypsins combined with a low concentration of LPS $(10 \mu \mathrm{g} / \mathrm{ml})$ we found that the IL-8 levels after combined exposure were significantly higher than the sum of the levels generated by either of the agents alone. This indicates a synergistic effect of seafood trypsin and LPS at these concentrations. With the higher concentrations of either type of seafood trypsins (Figure 3A and 3B) or LPS (Figure 4), this synergism was no longer evident, indicating that the effect is concentration dependent. These results provide an important new insight into the effects of exposure to mixture of these agents. Therefore, exposure to relatively low concentrations of LPS together with relatively low concentrations of seafood trypsin may cause a considerably augmented inflammatory response in airway cells due to the synergistic interactions between the exposure agents. 
Previous studies have demonstrated that the prototype LPS receptor, TLR-4, and the serine protease receptor PAR-2 interact at the level of cross talk between signalling pathways, which augment the inflammatory signals (Gieseler et al., 2013; Rallabhandi et al., 2008). Rallabhandi suggested an interaction between the two hetero-receptors via a MyD88-dependent pathway (Rallabhandi et al., 2008). Receptor cooperativity involving the PAR-2 and TLR-4 receptors may thus offer a likely explanation of the augmented inflammatory signalling observed with concomitant exposure to seafood trypsins and LPS. Further research is required to elucidate the mechanistic details and physiological significance of this interaction.

\section{Conclusions}

We conclude that bacterial LPS induces the secretion of the inflammatory mediator IL-8 in a dose-dependent manner in the A549 human pulmonary epithelial cell model. We also demonstrate that mixtures of LPS and seafood trypsins have combined effects, augmenting the generation of the transcription factor NF- $\kappa \mathrm{B}$ and synergistically enhancing the secretion of IL-8. According to the present findings, our data suggest that exposure to mixtures of environmental LPS and seafood trypsin may elicit an inflammatory response in the airway. This response may vary depending on the seafood species and the concentrations of LPS and proteases in the environment. Further research focusing on the exposure levels of seafood trypsin and endotoxins (LPS) in occupational environments, as well as epidemiological studies, is required to confirm the role of mixed exposures in the generation of airway symptoms in workers of the seafood industry.

\section{Acknowledgements}

This work was supported by the Northern Norway Regional Health Authority (Helse Nord RHF), 8038 (Bodø), Norway. The authors sincerely thank Dr. Nils Peder Willassen (UiT The Arctic University of Norway) for kindly providing purified salmon trypsin and Dr. Galina N. Rudenskaia (Moscow State University, Russia) for kindly providing 
purified king crab trypsin. The authors earnestly thank Merethe Larsen (University Hospital North Norway, Troms $\emptyset$, Norway) for technical assistance in the laboratory. 


\section{References}

al-Dagal M and Fung DY. (1990) Aeromicrobiology--a review. Critical Reviews in Food Science and Nutrition 29(5): 333-340.

Asokananthan N, Graham PT, Fink J, et al. (2002) Activation of protease-activated receptor (PAR)-1, PAR2 , and PAR-4 stimulates IL-6, IL-8, and prostaglandin E2 release from human respiratory epithelial cells. Journal of Immunology 168(7): 3577-3585.

Aul R, Armstrong J, Duvoix A, et al. (2012) Inhaled LPS challenges in smokers: a study of pulmonary and systemic effects. British Journal of Clinical Pharmacology 74(6): 1023-1032.

Bang B, Aasmoe L, Aamodt BH, et al. (2005) Exposure and airway effects of seafood industry workers in northern Norway. Journal of Occupational and Environmental Medicine 47(5): 482-492.

Bang B, Larsen M, Larsen AK, et al. (2009) Proteases from salmon stimulate IL-8 in airway epithelial cells. Journal of Toxicology and Environmental Health. Part A 72(9): 571-573.

Bhagwat SS, Larsen AK, Winberg JO, et al. (2014) Salmon and king crab trypsin stimulate interleukin-8 and matrix metalloproteinases via protease-activated receptor-2 in the skin keratinocytic $\mathrm{HaCaT}$ cell line. Food and Chemical Toxicology 69: 303-311.

Bhat RK, Page K, Tan A, et al. (2003) German cockroach extract increases bronchial epithelial cell interleukin-8 expression. Clinical and Experimental Allergy 33(1): 35-42.

Boyd CA, Weiler MH and Porter WP. (1990) Behavioral and neurochemical changes associated with chronic exposure to low-level concentration of pesticide mixtures. Journal of Toxicology and Environmental Health 30(3): 209-221.

Chi L, Li Y, Stehno-Bittel L, et al. (2001) Interleukin- 6 production by endothelial cells via stimulation of protease-activated receptors is amplified by endotoxin and tumor necrosis factor-alpha. Journal of Interferon and Cytokine Research 21(4): 231-240.

Erlanger BF, Kokowsky N and Cohen W. (1961) The preparation and properties of two new chromogenic substrates of trypsin. Archives of Biochemistry and Biophysics 95: 271-278.

Gieseler F, Ungefroren H, Settmacher U, et al. (2013) Proteinase-activated receptors (PARs) - focus on receptor-receptor-interactions and their physiological and pathophysiological impact. Cell Commun Signal 11: 86.

Guha M and Mackman N. (2001) LPS induction of gene expression in human monocytes. Cellular Signalling 13(2): 85-94.

Hernandez LV, Gonzalo S, Castro M, et al. (2011) Nuclear factor kappaB is a key transcription factor in the duodenal contractility alterations induced by lipopolysaccharide. Experimental Physiology 96(11): 1151-1162.

Hong JH, Lee SI, Kim KE, et al. (2004) German cockroach extract activates protease-activated receptor 2 in human airway epithelial cells. Journal of Allergy and Clinical Immunology 113(2): 315-319.

Jeebhay MF and Cartier A. (2010) Seafood workers and respiratory disease: an update. Current Opinion in Allergy and Clinical Immunology 10(2): 104-113.

Jeebhay MF, Robins TG, Lehrer SB, et al. (2001) Occupational seafood allergy: a review. Occupational and Environmental Medicine 58(9): 553-562.

Kartono F and Maibach HI. (2006) Irritants in combination with a synergistic or additive effect on the skin response: an overview of tandem irritation studies. Contact Dermatitis 54(6): 303-312.

Kato T, Takai T, Fujimura T, et al. (2009) Mite serine protease activates protease-activated receptor-2 and induces cytokine release in human keratinocytes. Allergy 64(9): 1366-1374.

Kauffman HF, Tomee JF, van de Riet MA, et al. (2000) Protease-dependent activation of epithelial cells by fungal allergens leads to morphologic changes and cytokine production. Journal of Allergy and Clinical Immunology 105(6 Pt 1): 1185-1193. 
Larsen AK, Seternes O-M, Larsen M, et al. (2011) Purified sardine and king crab trypsin display individual differences in PAR-2-, NF-KB-, and IL-8 signaling. Toxicological and Environmental Chemistry 93(10): 1991-2011.

Larsen AK, Seternes OM, Larsen M, et al. (2008) Salmon trypsin stimulates the expression of interleukin-8 via protease-activated receptor-2. Toxicology and Applied Pharmacology 230(3): 276-282.

Lee SE, Kim JM, Jeong SK, et al. (2010) Protease-activated receptor-2 mediates the expression of inflammatory cytokines, antimicrobial peptides, and matrix metalloproteinases in keratinocytes in response to Propionibacterium acnes. Archives for Dermatological Research. Archiv für Dermatologische Forschung 302(10): 745-756.

Liebers V, Bruning T and Raulf-Heimsoth M. (2006) Occupational endotoxin-exposure and possible health effects on humans. American Journal of Industrial Medicine 49(6): 474-491.

Michel O. (2001) Role of house-dust endotoxin exposure in aetiology of allergy and asthma. Mediators of Inflammation 10(6): 301-304.

Michel O. (2003) Role of lipopolysaccharide (LPS) in asthma and other pulmonary conditions. Journal of Endotoxin Research 9(5): 293-300.

Michel O, Dentener M, Cataldo D, et al. (2007) Evaluation of oral corticosteroids and phosphodiesterase4 inhibitor on the acute inflammation induced by inhaled lipopolysaccharide in human.

Pulmonary Pharmacology and Therapeutics 20(6): 676-683.

O'Grady NP, Preas HL, Pugin J, et al. (2001) Local inflammatory responses following bronchial endotoxin instillation in humans. American Journal of Respiratory and Critical Care Medicine 163(7): 15911598.

Ostrowska E, Sokolova E and Reiser G. (2007) PAR-2 activation and LPS synergistically enhance inflammatory signaling in airway epithelial cells by raising PAR expression level and interleukin-8 release. American Journal of Physiology: Lung Cellular and Molecular Physiology 293(5): L12081218.

Outzen H, Berglund GI, Smalas AO, et al. (1996) Temperature and pH sensitivity of trypsins from Atlantic salmon (Salmo salar) in comparison with bovine and porcine trypsin. Comparative Biochemistry and Physiology. Part B: Biochemistry and Molecular Biology 115(1): 33-45.

Page K, Hughes VS, Bennett GW, et al. (2006) German cockroach proteases regulate matrix metalloproteinase-9 in human bronchial epithelial cells. Allergy 61(8): 988-995.

Rallabhandi P, Nhu QM, Toshchakov VY, et al. (2008) Analysis of proteinase-activated receptor 2 and TLR4 signal transduction: a novel paradigm for receptor cooperativity. Journal of Biological Chemistry 283(36): 24314-24325.

Reddi K, Phagoo SB, Anderson KD, et al. (2003) Burkholderia cepacia-induced IL-8 gene expression in an alveolar epithelial cell line: signaling through CD14 and mitogen-activated protein kinase. Pediatric Research 54(3): 297-305.

Rudenskaia GN, Isaev VA, Kalebina TS, et al. (1998) [Isolation of trypsin PC from the Kamchatka crab Paralithodes camtschatica and its properties]. Bioorganicheskaia Khimiia 24(2): 112-118.

Rylander R. (2002) Endotoxin in the environment--exposure and effects. Journal of Endotoxin Research 8(4): 241-252.

Schwartz DA, Thorne PS, Yagla SJ, et al. (1995) The role of endotoxin in grain dust-induced lung disease. American Journal of Respiratory and Critical Care Medicine 152(2): 603-608.

Shiryaeva O, Aasmoe L, Straume B, et al. (2014) Respiratory effects of bioaerosols: exposure-response study among salmon-processing workers. American Journal of Industrial Medicine 57(3): 276285.

Sun G, Stacey MA, Schmidt M, et al. (2001) Interaction of mite allergens Der p3 and Der p9 with protease-activated receptor-2 expressed by lung epithelial cells. Journal of Immunology 167(2): 1014-1021. 
Thorn J. (2001) The inflammatory response in humans after inhalation of bacterial endotoxin: a review. Inflammation Research 50(5): 254-261.

Vliagoftis H, Befus AD, Hollenberg MD, et al. (2001) Airway epithelial cells release eosinophil survivalpromoting factors (GM-CSF) after stimulation of proteinase-activated receptor 2. Journal of Allergy and Clinical Immunology 107(4): 679-685.

Wade MG, Foster WG, Younglai EV, et al. (2002) Effects of subchronic exposure to a complex mixture of persistent contaminants in male rats: systemic, immune, and reproductive effects. Toxicological Sciences 67(1): 131-143.

Zhang $G$ and Ghosh S. (2000) Molecular mechanisms of NF-kappaB activation induced by bacterial lipopolysaccharide through Toll-like receptors. Journal of Endotoxin Research 6(6): 453-457. 
Figures and legends

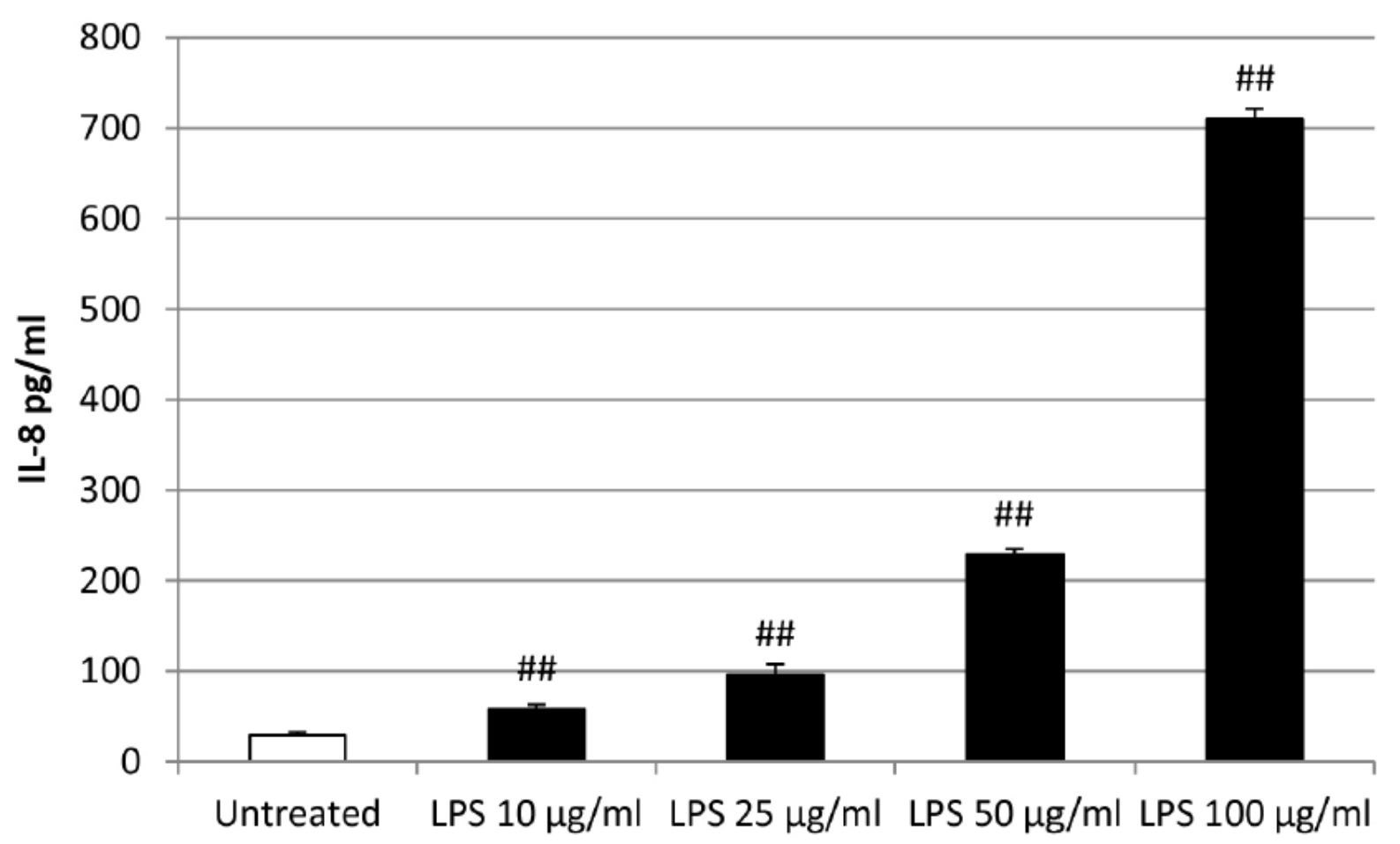

Figure 1. Effect of LPS (endotoxin) on secretion of IL-8 in A549 cells. A549 cells were seeded into 12-well plates at a density of $1 \times 10^{5}$ cells/well. After 48 hours, the cells were subjected to starvation in a serum-free medium. Then, 24 hours later, the cells were incubated with the indicated concentrations of LPS for 6 hours. The supernatant was analysed for the presence of IL8 with an ELISA. The data are presented as the means \pm S.D.; $n=6$ from three individual experiments. (\#\# $p<0.01$ compared with untreated cells.) 


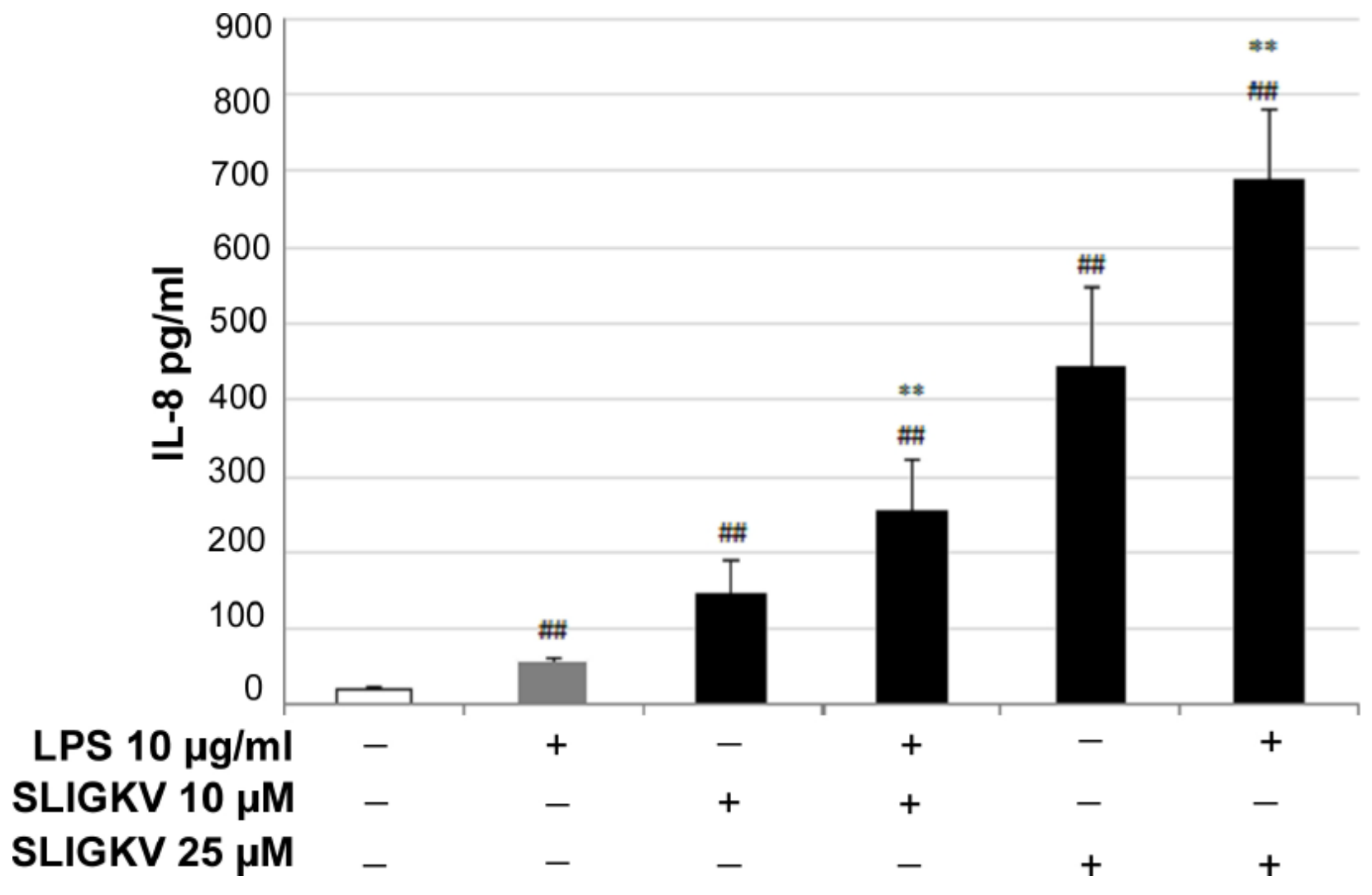

Figure 2. Effect of LPS (endotoxin) and SLIGKV-NH2 on the secretion of IL-8 in human pulmonary epithelial cells. A549 cells were seeded into 12 -well plates at a density of $1 \times 10^{5}$ cells/well. After 48 hours, the cells were subjected to starvation in serum-free medium. Then, 24 hours later, the cells were incubated with the indicated concentrations of SLIGKV- $\mathrm{NH}_{2}$ and LPS for 6 hours. The supernatant was analysed for the presence of IL-8 with an ELISA. The data are presented as the means \pm S.D.; $\mathrm{n}=6$ from three individual experiments. (\#\# $p<0.01$ compared to the untreated cells; $* * p$ $<0.01$ compared to the cells treated with SLIGKV- $\mathrm{NH}_{2}$ alone.) 


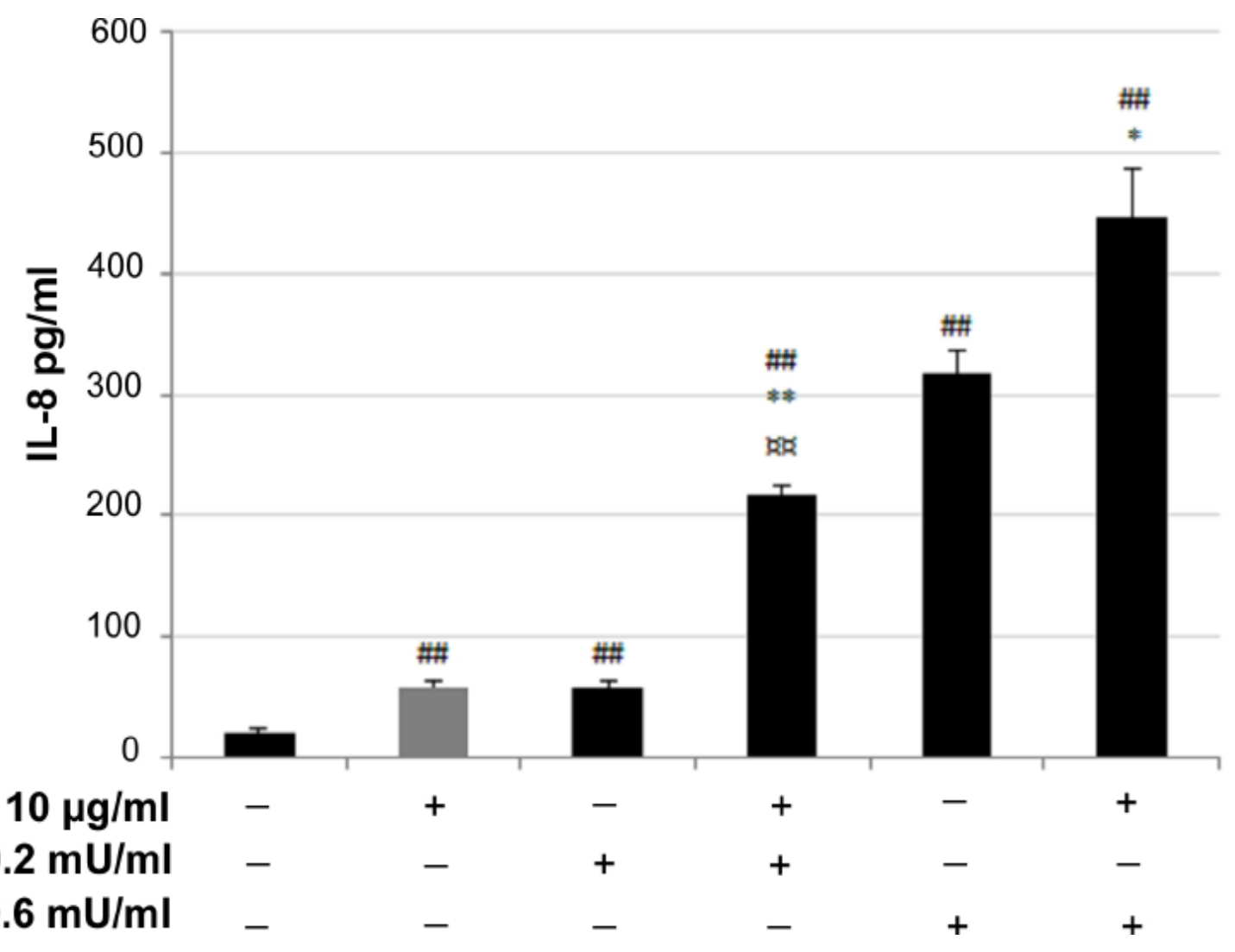

Figure 3A: Salmon trypsin and LPS synergistically induce secretion of IL-8 in A549 cells. A549 cells were seeded into 12- well plates at a density of $1 \times 10^{5}$ cells/well. After 48 hours, the cells were subjected to starvation in serum-free medium. Then, 24 hours later, the cells were incubated with the indicated concentrations of purified salmon trypsin and LPS $(10 \mu \mathrm{g} / \mathrm{ml})$ for 6 hours. The supernatant was analysed for the presence of IL-8 with an ELISA. The data are presented as the mean \pm S.D.; $n=6$ from three individual experiments. (\#\# $p<0.01$ compared to the untreated cells; $* p<0.05$, ${ }^{* *} p<0.01$ compared to cells treated with purified salmon trypsin alone; $000<0.01$ compared to the cells treated with purified salmon trypsin alone + LPS alone.) 


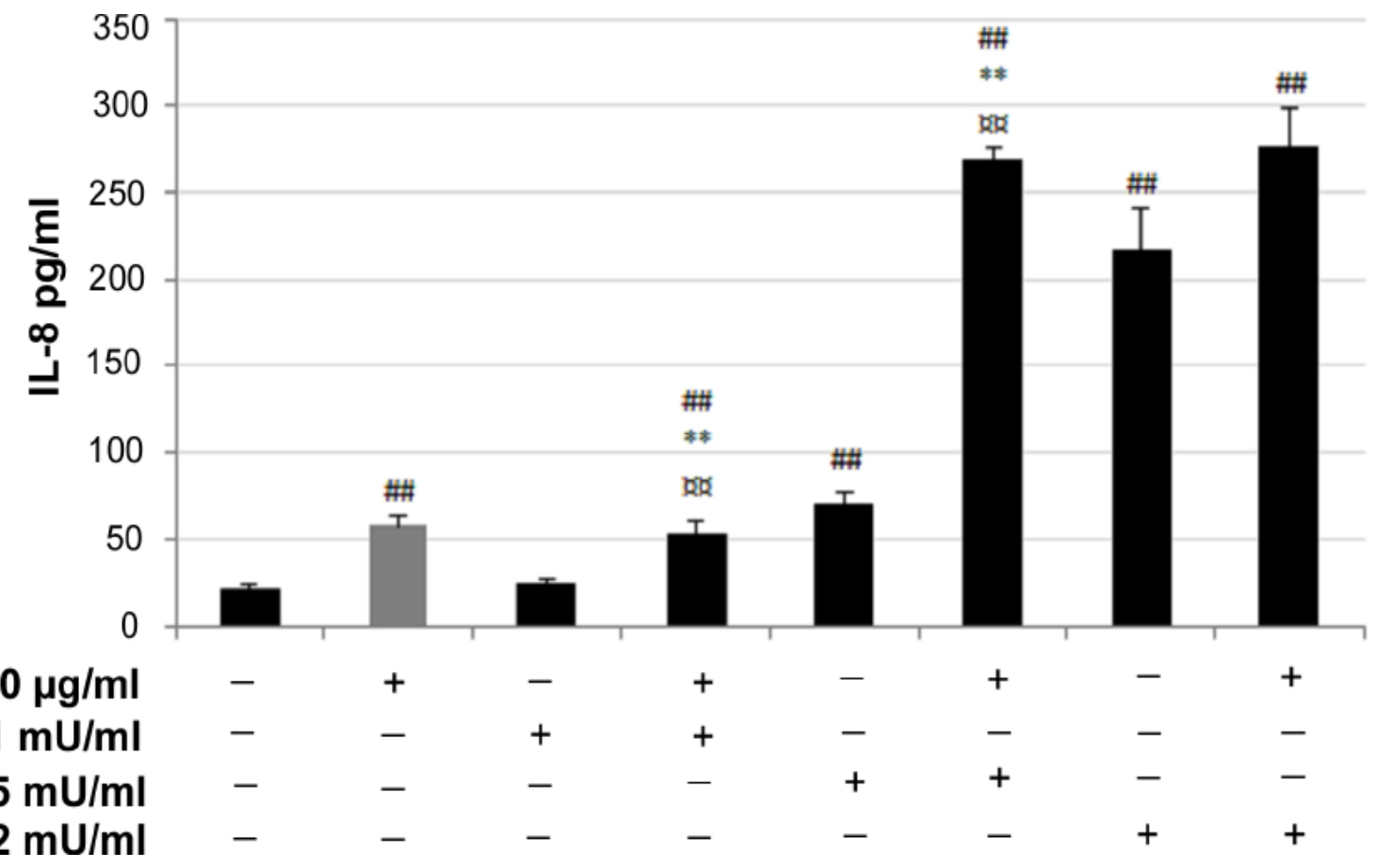

Figure 3B. King crab trypsin and LPS synergistically induce secretion of IL-8 in A549 cells. A549 cells were seeded into 12 -well plates at a density of $1 \times 10^{5}$ cells/well. After 48 hours, the cells were subjected to starvation in serum-free medium. Then, 24 hours later, the cells were incubated with the indicated concentrations of purified king crab trypsin and LPS $(10 \mu \mathrm{g} / \mathrm{ml})$ for 6 hours. The supernatant was analysed for the presence of IL-8 with an ELISA. The data are presented as the means \pm S.D.; $n=6$ from three individual experiments. (\#\# $p<0.01$ compared to the untreated cells, ${ }^{* *} p<0.01$ compared to the cells treated with purified king crab trypsin alone; $p<0.01$ compared to the cells treated with purified king crab trypsin alone + LPS alone.) 


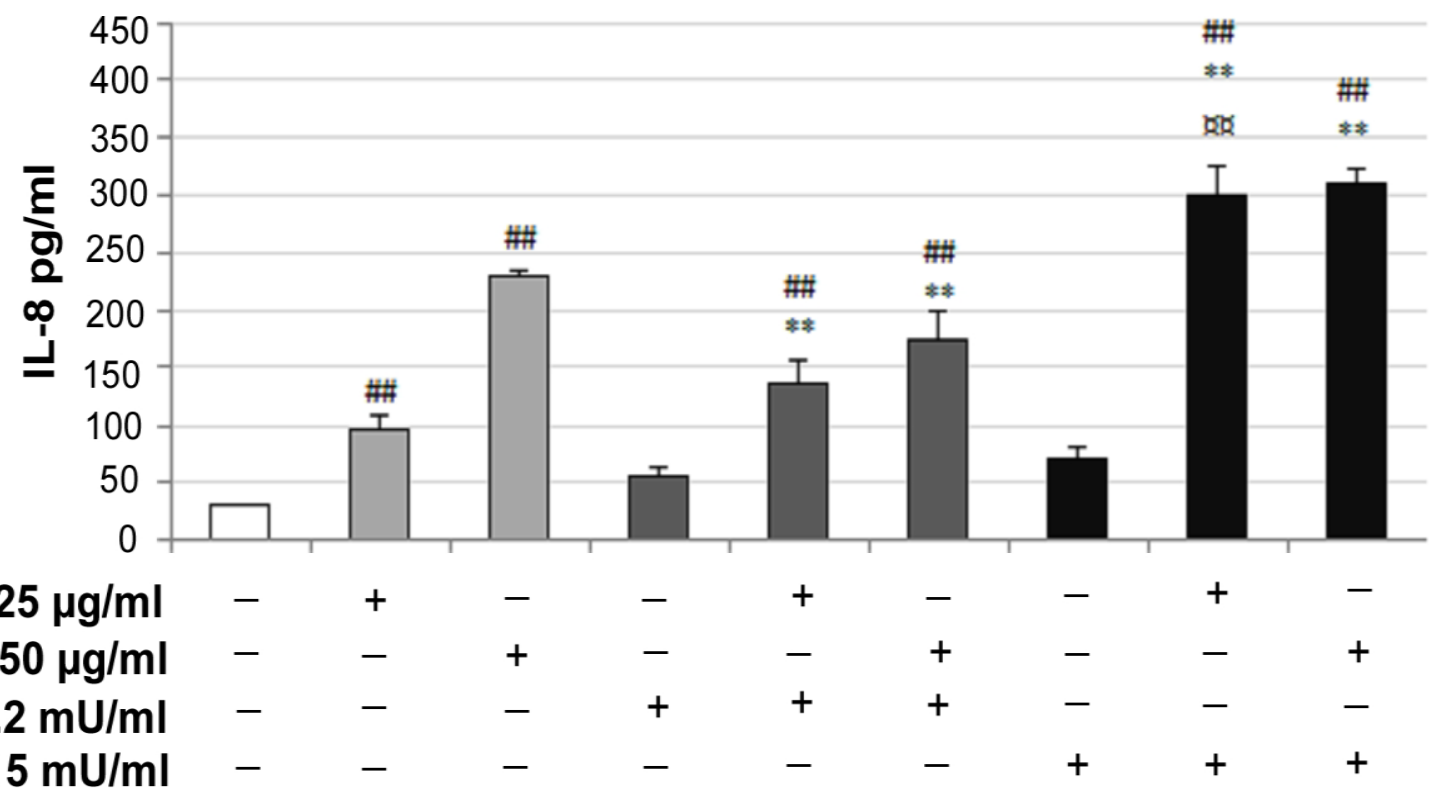

Figure 4. Effect of variable LPS (endotoxin) concentrations. A549 cells were seeded into 12-well plates at a density of $1 \times 10^{5}$ cells/well and cultured until reaching 80-90\% confluency. After 48 hours, the cells were subjected to starvation in serum-free medium for 24 hours, and the cells were then incubated with the indicated concentrations of purified salmon trypsin or king crab trypsin and/or LPS for 6 hours. The supernatants were analysed for the presence of IL-8 with an ELISA. The data are presented as the mean \pm S.D.; $\mathrm{n}=6$ from three individual experiments.(\#\# $p<0.01$ compared to the untreated cells; $* * p<$ 0.01 compared to the cells treated with purified salmon or king crab trypsin alone; $000<0.01$ compared to the cells treated with purified king crab trypsin alone + LPS alone.) 


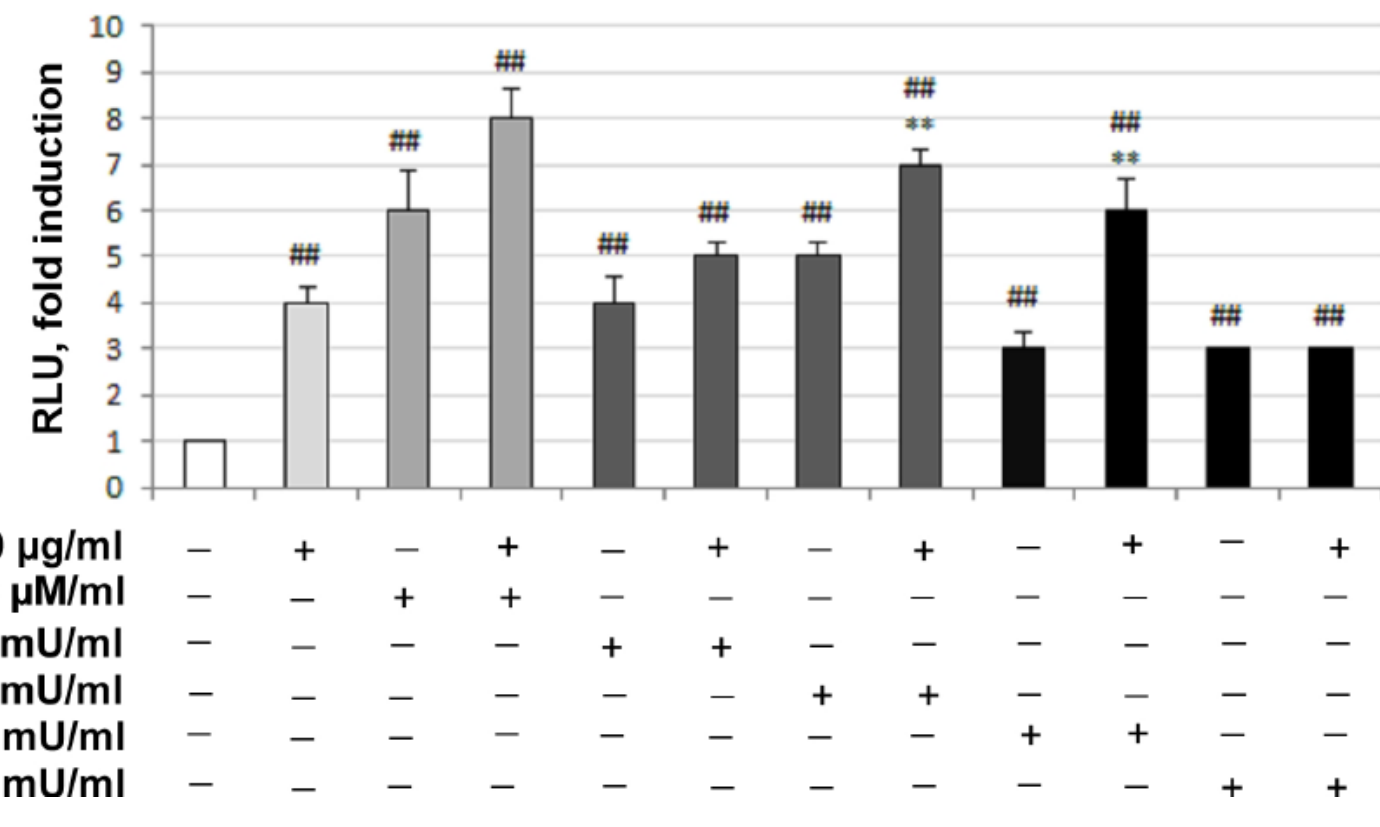

Figure 5. Effect of the mixture of LPS with SLIGKV-NH2 or the salmon or king crab

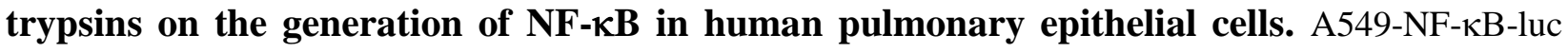
cells were seeded into 12-well plates at a density of $1 \times 10^{5}$ cell/well and grown until the cells were 80$90 \%$ confluent. The cells were then subjected to starvation in serum-free medium for 24 hours followed by incubation with the indicated concentrations of the purified salmon or king crab trypsins and/or LPS. After 6 hours, the cells were lysed with a lysis buffer, and the lysates were analysed for luciferase activity. The results were normalised against the total protein concentration and expressed as a fold induction above the basal level. The data are presented as the mean \pm S.D.; $\mathrm{n}=6$ from three individual experiments. $(\# \# p<$ 0.01 compared to the untreated cells; $* * p<0.01$ compared to the cells treated with purified salmon or king crab trypsin alone.) 